Article

\title{
Development of a Novel Climate Adaptation Algorithm for Climate Risk Assessment
}

\author{
Ching-Pin Tung ${ }^{1}$, Jung-Hsuan Tsao ${ }^{1}$, Yu-Chuan Tien ${ }^{1}$, Chung-Yi Lin ${ }^{1} \mathbb{D}$ and \\ Bing-Chen Jhong $2, *$ (D)
}

1 Department of Bioenvironmental Systems Engineering, National Taiwan University, Taipei 10617, Taiwan; cptung@ntu.edu.tw (C.-P.T.); b93602018@ntu.edu.tw (J.-H.T.); erictien1234@gmail.com (Y.-C.T.); philip928lin@gmail.com (C.-Y.L.)

2 Department of Civil and Earth Resources Engineering, Graduate School of Engineering, Kyoto University, Kyoto 615-8540, Japan

* Correspondence: jhongbc0516@gmail.com; Tel.: +81-75-383-3153

Received: 21 February 2019; Accepted: 6 March 2019; Published: 8 March 2019

check for updates

\begin{abstract}
To comprehensively assess the climate risk originating from climate change, this study aims at developing a novel climate adaptation algorithm, representing not only on the basis of Climate Change Adaptation Six Steps (CCA6Steps), but also innovations in climate risk template. The climate risk template is proposed as a climate risk analysis tool based on the procedure of CCA6Steps, including the identification of problems and objectives, the analysis of current and future risks, and the assessment of adaptation options, to identify the relationship between the climate risk components, including hazard, exposure, and vulnerability. An application is implemented to demonstrate the advantages of the proposed algorithm in this study. The results show that the problems and objectives which concern the governance level and stakeholders can be clearly identified by the proposed algorithm. The relationship between climate-related hazards, exposure, and vulnerability of the protected target can also be precisely investigated. Furthermore, the climate adaptation strategies able to mitigate the impact of hazards on the protected target are further discussed in this study. In summary, the proposed climate adaptation algorithm is expected to provide a standard operating procedure and be a useful tool to support climate risk assessment.
\end{abstract}

Keywords: climate adaptation algorithm; climate risk assessment; climate risk adaptation; climate change adaptation six steps

\section{Introduction}

Evaluation of the impact of climate change on extremes is a key challenge for adaptation planning [1]. All nations in the world are facing the threat of climate change and developing adaptation plans in response to climate change [2-4]. Cities have to globally face considerable risks originated from climate change [2]. The impact of climate change on precipitation has consequently been a crucial issue and become a kind of potential hazard due to the vulnerability and exposure of societies $[5,6]$. Moreover, possible changes in climate extremes may significantly influence the environment, such as flooding and inundation due to heavy precipitation.

Recently, the definition of climate risk has been conceptualized as a significant integrative viewpoint in the Fifth Assessment Report (AR5) of IPCC. A logical framework for integrating traditional different perspectives from climate adaptation is also provided by the definition of climate risk, including the investigation of hazard, exposure, and vulnerability [7]. Furthermore, several previous studies have indicated the important role of climate risk reduction in climate change adaptation [8-11]. On the one hand, risk communication among decision-makers, stakeholders, and the 
public can affect efforts at all levels in climate adaptation planning. On the other hand, non-consensus communication may become an obstacle to policy adoption for decision-makers [12]. Therefore, a structure of systematically integrating climate risk assessment for supporting risk communication is desired.

To assist the decision-making of climate change adaptation, a systematically integrated adaptation procedure is necessary for stakeholders. Several well-known adaptation tools and frameworks are released to assist in making adaptation plans, such as the UK Climate Impacts Programme (UKCIP) Adaptation Wizard, United Nations Development Programme-Adaptation Policy Framework (UNDP-APF), and Climate-ADAPT. The UKCIP was established by the UK Government in 1997. It provides information to help decision-makers plan their response to the impacts of climate change. The Wizard is a 5-step process to help decision makers assess a system's vulnerability to current climate and future climate change, identify options to address key climate risks, and implement a climate change adaptation strategy plan [13].

As for UNDP-APF, by both reducing potential negative impacts and enhancing any beneficial consequences of a changing climate, the APF provides guidance on designing and implementing projects that reduce vulnerability to climate change. Moreover, APF integrates national policy-making efforts with a "bottom-up" movement. UNDP-APF emphasizes five major principles: adaptation policy and measures are assessed in a developmental context; adaptation to short-term climate variability and extreme events are explicitly included as a step toward reducing vulnerability to long-term change; adaptation occurs at different levels in society, including the local level; the adaptation strategy and the process by which it is implemented are equally important; and building adaptive capacity to cope with current climate is one way of preparing society to better cope with future climate [14]. Another tool is the European Adaptation Support Tool (i.e., Climate-ADAPT). The aim of the Adaptation Support Tool is to assist users in developing climate change adaptation strategies and plans by providing guidance, links to relevant sources and dedicated tools. The steps and recommendations of the Adaptation Support Tool are listed as follows: (1) Preparing the Ground for Adaptation, (2) Assessing Risks and Vulnerabilities to Climate Change, (3) Identifying Adaptation Options, (4) Assessing Adaptation Options, (5) Implementation, (6) Monitoring and Evaluation. Climate-ADAPT provided a clear principle; nevertheless, users still need the enforcement rules to accomplish the whole cycle.

To systematically assess climate risk and identify climate adaptation strategies, a tool with a standard operational procedure for climate risk assessment is necessary. Nevertheless, a specific qualitative method for interdisciplinary assessment of climate risk has rarely been developed and provided as a fundamental principle for climate adaptation strategies based on a crucial concept of climate risk defined by the IPCC. In addition, the systematic integrative tool for climate risk assessment is essentially integrated with climate adaptation steps. Therefore, it prompted us to investigate the interdisciplinary assessment of climate risk in this study.

The purpose of this study is to comprehensively assess the climate risk originating from climate change. For this purpose, a climate adaptation algorithm, integrating climate risk templates on the basis of Climate Change Adaptation Six Steps (CCA6Steps), is proposed to precisely clarify the relationship between the hazard, exposure, and vulnerability of climate risk in this study. CCA6Steps is mainly based on the conceptions of UKCIP, UNDP-APF, and Climate-ADAPT. Climate risk templates are employed as analysis tools for climate risk assessment on each step of CCA6Steps. Moreover, the model-based concept helps users to mechanize climate change evaluation. Hence, the decomposed risk factors in this study identify a standard information flow. The specific input data, tool, and result would be recognized in each step. An application is implemented to clearly demonstrate the advantages of the proposed algorithm. The proposed algorithm is expected to be valuable for climate risk assessment.

\section{Proposed Climate Adaptation Algorithm}

In this study, a climate adaptation algorithm, based on the procedure of CCA6Steps integrated with the climate risk template, is developed to assess climate risk and to support risk assessment. 
The algorithmic procedure avoids confusion in the process of climate risk evaluation and adaptation assessment. Three main directions of CCA6Steps are problem identification, current and future risk assessment, and climate adaptation strategies, respectively. The brief introduction of CCA6Steps is clearly discussed in Section 2.1. Besides the analysis procedure of climate change adaptation, the climate risk components are able to be investigated by the climate risk template, as described in Section 2.2. The procedure of climate risk assessment including the operation of the climate risk template within CCA6Steps is shown in Section 2.3.

\subsection{Climate Change Adaptation Six Steps}

CCA6Steps is a systematic procedure to assist the development of interdisciplinary and cross-sectoral climate adaptation strategies. CCA6Steps consists of the following steps: (1) Identifying Problems and Objectives, (2) Assessing and Analyzing Current Risk, (3) Assessing and Analyzing Future Risk, (4) Identifying and Assessing Adaptation Options, (5) Planning and Implementing Adaptation Pathway, and (6) Monitoring and Modifying Adaptation Pathway, as shown in Figure 1. The step of Identifying Problems and Objectives includes starting up adaptation committee, key issue definition, interdisciplinary analyzing, and goal setting. In order to develop an adaptation plan with proper planning, an adaptation committee of stakeholders is needed. The concept of committee with stakeholders involved is similar to Shared Vision Planning (SVP), where public participation plays an important role to increase trust and credibility for the adaptation strategy [15]. Palmer et al. [16] suggested using SVP for public involvement, since it has been applied in a variety of scenarios in the last two decades. Langsdale et al. [17] also mentioned that SVP is a good way to link research, public input, and decision making across geographic regions, stakeholder groups, and different experts. Richards et al. [18] indicated that stakeholder participation may increase public trust in decisions and civil society; it may also increase the likelihood that the decisions are perceived to be holistic and fair. Reed et al. [19] mentioned that engagement with stakeholders as early as possible in decision-making can lead to high quality and durable decisions. Broad et al. [20] suggested that when water allocation committee is discussing water discharge scenarios, local stakeholders' involvement can lead to less biased options. Obviously, the previous studies showed that stakeholder participation can enhance the quality of the decisions made by the government. Therefore, the key issue and interdisciplinary analysis should be conducted by the committee. The committee is also responsible for the adaptation goal setting following the steps of CCA6Steps.

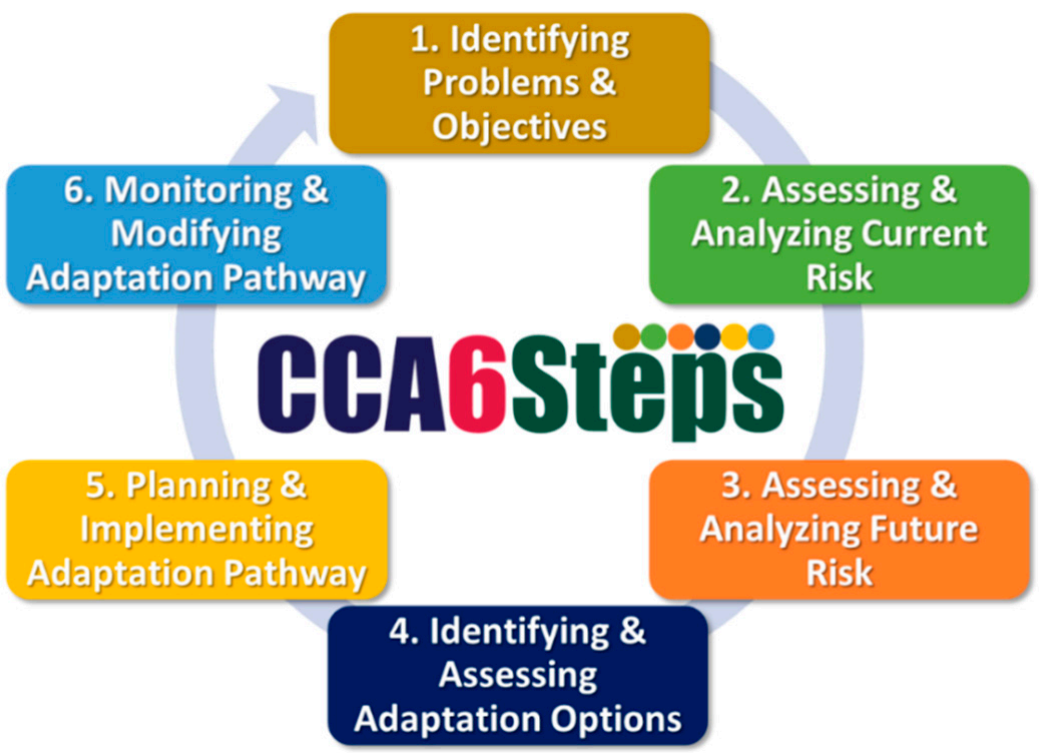

Figure 1. The procedure of Climate Change Adaptation Six Steps (CCA6Steps). 
The second step of CCA6Steps, Assessing and Analyzing Current Risk, analyzes and uses models to evaluate the climate risk of historical and current events. By surveying previous researches and databases of climate events, causes and hotspots of climate risk can be analyzed. Models used to evaluate the risk need to be calibrated first, then the current risk can be evaluated by the models and cause of climate risk. In the next step of CCA6Steps, Assessing and Analyzing Future Risk, the future and baseline scenarios of climate change and socioeconomics should be considered in the models used in the second step to analyze future risk. In this step, future scenarios can be decided by selecting proper global circulation models (GCMs) and representative concentration pathways (RCPs) of climate change and socioeconomic factors, such as population growth and land use change. By comparing baseline and future scenarios, future risk can be calculated.

According to the analyzed results in assessing and analyzing current and future risk steps, the climate adaptation options should be identified and assessed in the fourth step (Identifying and Assessing Adaptation Options). The identification of adaptation options should be specifically implemented based on local conditions and causes of risk, including hazard, exposure, and vulnerability. In the fifth step, Planning and Implementing Adaptation Pathway, the selected adaptation options are further used to establish adaptation pathways and implementing plans. In other words, the adaptation pathways can be implemented by combining the selected adaptation options with considering the cost, benefit, and tipping points for the considered scenarios [21]. Moreover, the committee should be responsible for making the implementing plan, including the priority of the adaptation options and pathway changing conditions.

The final step of CCA6Steps is Monitoring and Modifying Adaptation Pathway, which focuses on the implementation of monitoring and modifying adaptation pathways based on the planning of adaptation pathways. The adaptation committee should decide how to monitor key factors of climate risk, and whether the inspection of the adaptation plan is still working well. In addition, a modifying plan should be made to identify that the whole adaptation strategy is still functional in response to the influence of climate change. The objective of this study is focused on climate risk assessment, and the first to fourth steps are highlighted to assess the causes of climate risk in this study.

\subsection{Climate Risk Template}

In order to comprehend the component factors of climate risk and further provide a standard analysis procedure for central and local governments or organizations, the climate risk template is proposed as a climate risk analysis tool for the assistance of climate risk communication with each other. As shown in Figure 2, the relationship between each component, including hazard, exposure, and vulnerability, with different composed factors can be specifically and clearly illustrated to help users figure out the causes of climate risk. In the climate risk template, the key issue, the protected target, and critical factors should be defined based on the core concept of climate risk definition by IPCC AR5. To help the governance level or other users to understand the kinds of tools establishing the relationship between considered input and desired output, the proposed algorithm of climate risk assessment for presenting tools and indicators is shown in Figure 3. Moreover, the metadata table of the proposed algorithm for climate risk assessment, which is developed on the basis of the climate risk template including risk, hazard, vulnerability, exposure, and their categories, should also be listed to present each factor, data source, geographic units, and specific year corresponding to each category. In this study, the metadata table is employed as a tool to make users clearly understand the corresponding factor and data source in efficiently constructing meta-models if the construction procedure of existing tools requires a lot of computational time. Therefore, by operating the climate risk template, the adaptation committee is able to understand how the key factors affect climate risk and deal with that. The composed critical factors and their descriptions are listed as follows: 


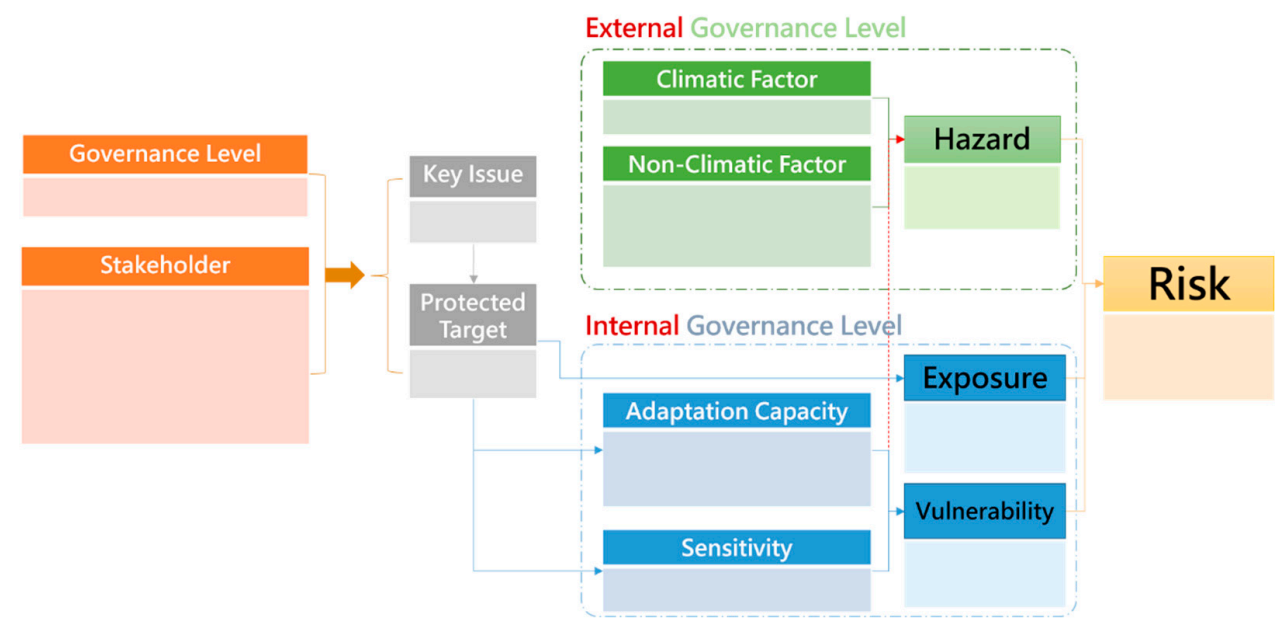

Figure 2. The proposed algorithm of climate risk assessment for investigating the relationship between factors.

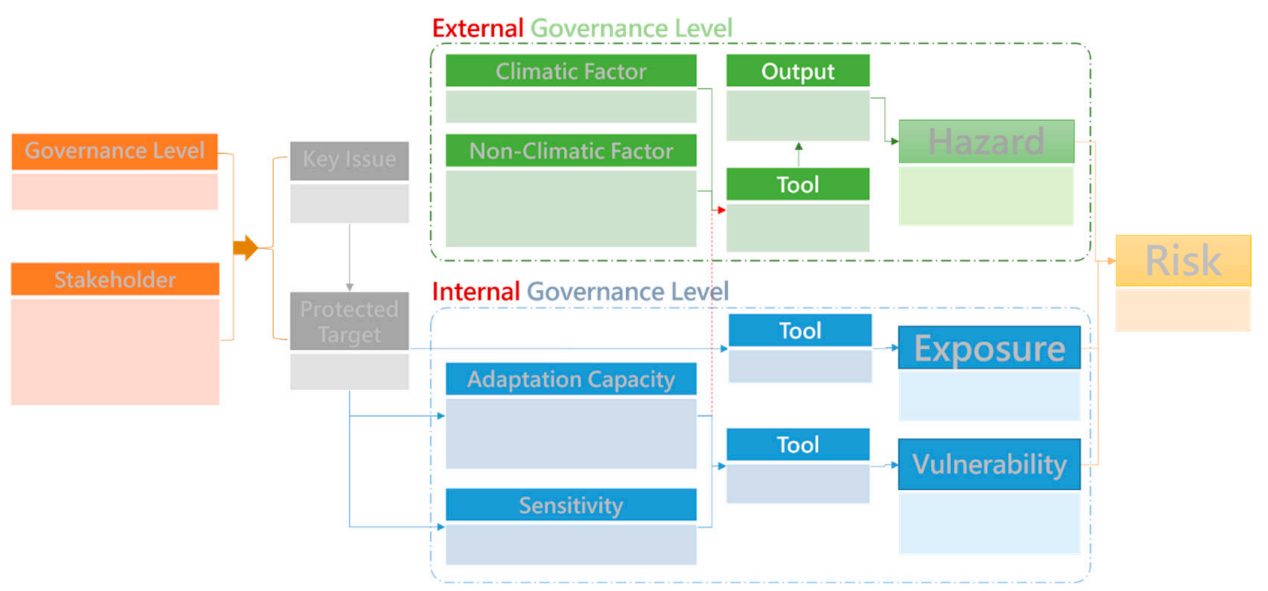

Figure 3. The proposed algorithm of climate risk assessment for presenting tools and indicators.

\subsubsection{Key Issue and Protected Target}

In the beginning, the key issue and protected target should be firstly discussed and determined in the climate risk template. Because of the loss of people's life, property, and natural systems like forests and wild animals, several historical events resulting from climate extremes should be paid attention. Historical events of disasters due to climate extremes and the corresponding protected targets can be found by searching news or reports. The protected target could be human, animal, factories, or other things affected by disasters.

\subsubsection{Governance Level and Stakeholders}

According to the determination of the key issue and protected target, the government and stakeholders should be secondly confirmed to understand the responsibility of the government and the relationship between that and stakeholders. However, it is also critical to further determine the level of government. In this study, three levels, which are central level, local level, and local organization, are suggested. Once the level is decided, the corresponding governance unit of the key issue is also determined. Furthermore, the stakeholders can be defined as people, industries, or the organizations affected by the key issue or hazard. The stakeholders can also be divided into two groups: internal and external stakeholders. The former is a part of the government department, while the latter is others such as the public, non-governmental organizations, industries, etc. Moreover, the government should invite all representatives of the stakeholders to discuss climate risk and adaptation. 


\subsubsection{Hazard}

In IPCC AR5, hazard usually refers to climate-related physical events, trend, or its physical impacts. In this study, hazard is defined as an event that could potentially cause loss or damage to the protected target. The driving forces of hazard include climatic factor and non-climatic factor, which represent the impact of climate change and the influence of anthropogenic activities, respectively. In addition, the evaluation of different levels of hazard is also important to specifically quantify the term of hazard. For example, the influences of inundation depths for 0.05 and $1.5 \mathrm{~m}$ on the protected target are obviously different. Therefore, the determination of the threshold or level of hazard is recommended to further evaluate the hazard.

\subsubsection{Exposure}

A protected target that we concern must be certainly defined for further quantifying their exposure and vulnerability. Exposure, defined by [7], refers to "the presence of people, livelihoods, species or ecosystems, environmental functions, services, and resources, infrastructure, or economic, social, or cultural assets in places and settings that could be adversely affected". Disasters induced by climate-related hazards, such as floods, affect millions of people in a natural system, which would lead to significant damages to people's safety and eco-environment $[22,23]$. The protected target can be anything to which people pay attention, both human systems and natural systems, so the exposure of the protected target is also diverse, such as population density. In this study, the exposure of the protected target is defined as the distribution of the protected target. Because of the influence of climate change and social-economic change in the future, the exposure of potential protected target should be comprehensively considered.

\subsubsection{Vulnerability}

Vulnerability is described as the propensity or predisposition to be adversely affected in IPCC reports. In this study, the vulnerability is simply defined as the combination of sensitivity and adaptation capacity. On the one hand, sensitivity means how easily the protected target is influenced by hazard. If the protected target is hardly influenced by the hazard and extreme climate events, the sensitivity is relatively low. Adaptation capacity, on the other hand, represents the measurements of the governance level for decreasing the impact of hazard. Each of the measurements can be regarded as a factor of adaptation capacity. However, measurements exceeding the management range of governance level (i.e., in the external governance level) should not be considered as adaptation capacity, and they should be considered as a part of the non-climate factor of a hazard. In this study, it is recommended that the factors of sensitivity and adaptation capacity are quantified as different levels to evaluate vulnerability indicator.

\subsection{Procedure of Climate Risk Assessment}

The proposed climate adaptation algorithm integrated with the climate risk template is developed based on the core concepts for climate risk resulting from the interaction of climate-related hazards with exposed and vulnerable natural systems and humans. In this study, the algorithm development for climate risk assessment is the crucial issue, so we focus on the operation of the climate risk template within the first to fourth steps of CCA6Steps. In addition to the qualification analysis of the causes of climate risk components, spatial information and visualization are also necessary to present the quantified results, especially for identifying climate adaptation strategies. Therefore, the assessment results in the form of risk maps are presented.

The exposure and vulnerability are normalized in the range of 0 to 1 . The form of exposure for normalization is written as the following:

$$
E_{i}^{\prime}=\frac{E_{i}-E_{\min }}{E_{\max }-E_{\min }}
$$


where $E_{\text {max }}$ and $E_{\text {min }}$ mean the maximum and minimum values of exposure, respectively; $E_{i}$ represents the exposure value of the $i$ th administrative district; $E_{i}^{\prime}$ denotes the normalized value of exposure in the $i$ th administrative district. In addition, the form of factors of vulnerability for normalization is written as the following:

$$
V_{j, i}^{\prime}=\frac{V_{j, i}-V_{j, \text { min }}}{V_{j, \text { max }}-V_{j, \text { min }}}
$$

where $V_{j, \text { min }}$ and $V_{j, \text { max }}$ mean the maximum and minimum values of the $j$ th factor of vulnerability, respectively; $V_{j, i}$ represents the $j$ th factor of vulnerability in the $i$ th administrative district; $V_{j, i}^{\prime}$ denotes the normalized value of the $j$ th factor of vulnerability in the $i$ th administrative district. Then, the final vulnerability index (FVI) can further be obtained, and its form is written as the following:

$$
F V I_{i}=\sum_{j=1}^{N_{v}} w_{j} \times V_{j, i}^{\prime}
$$

where $N_{v}$ represents the number of all factors of vulnerability, and $w_{j}$ means the weight for the $j$ th factor of vulnerability. The values of exposure and FVI can be further separated to different ranges $(0 \sim 0.2,0.2 \sim 0.4,0.4 \sim 0.6,0.6 \sim 0.8$, and $0.8 \sim 1)$ as different levels $(1,2,3,4$, and 5).

In addition to the level separation of exposure and vulnerability, the different levels of hazard component are also distinguished. In this study, the climate-related hazard is defined as inundation disaster. In general, because of the lack of observed measured data, the grid data of inundation depths simulated by numerical models are usually used. The form of hazard is written as the following:

$$
H_{i}=\sum_{k=1}^{D_{R}} \frac{N G_{k, i}}{A G_{i}} \times k
$$

where $H_{i}$ represents the value of hazard in the $i$ th administrative district; $D_{R}$ means the number of ranges of inundation depth; $N G_{k, i}$ denotes the number of grids in the $k$ th range of inundation depths in the $i$ th administrative district; $A G_{i}$ means all grid number in the $i$ th administrative district. In this study, the ranges of inundation depths are separated as $0 \sim 0.3,0.3 \sim 0.5,0.5 \sim 1,1 \sim 3$, and $3 \sim 5 \mathrm{~m}$. Then, the values of hazard can be further separated as 5 different levels. Finally, the level assessment matrix is used to obtain the level of exposure and vulnerability, as shown in Figure 4 . The concept of the level assessment matrix is widely used on risk assessment, including technological risks, political risks, risk with domestic climate, and social risks [24]. In IPCC AR4, a similar concept, qualitative definition of uncertainty, is also addressed, using the level of the agreement and the amount of the evidence to evaluate risk and uncertainty. Moreover, the risk assessment matrix is further employed to merge the levels of hazard, exposure, and vulnerability, and present the severity of climate risk.

(a)

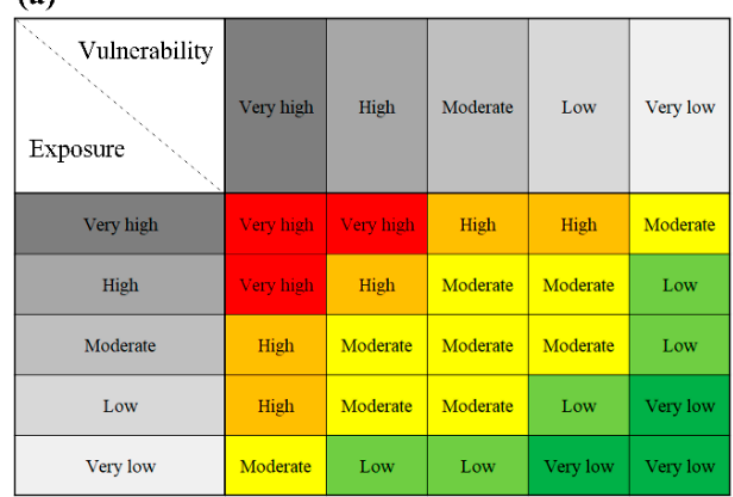

(b)

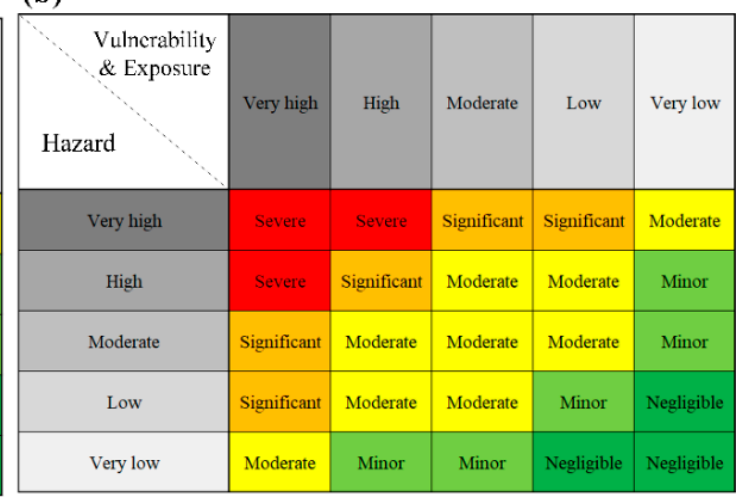

Figure 4. Level assessment matrix for (a) exposure and vulnerability, and risk assessment matrix for (b) levels of hazard, exposure, and vulnerability. 


\section{Study Area and Data}

Yilan County (Figure 5), situated in the northeastern coast of Taiwan, with an area of approximately $2143 \mathrm{~km}^{2}$, is selected as the study area in this paper. The 12 administrative districts of Yilan County are listed in Table 1. It is a relatively isolated area surrounded by natural geographical boundaries, and also has a subtropical monsoon climate. In average, two to three typhoons statistically hit Taiwan each year in summer and autumn, $45 \%$ of which make landfall in this area [25]. The annual average precipitation ranges between $2000 \mathrm{~mm}$ and $2500 \mathrm{~mm}$. Severe events of inundation disaster rapidly occur in low-lying areas during typhoons.
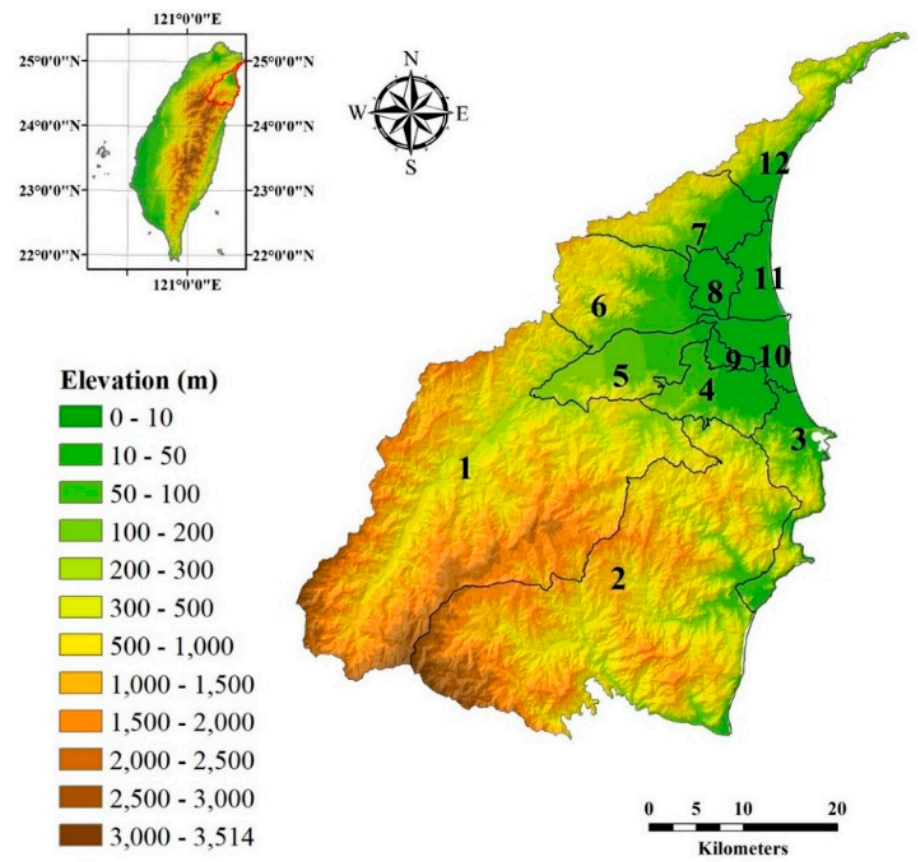

Figure 5. The study area and its administrative districts.

Table 1. The corresponding number for each administrative district of the study area.

\begin{tabular}{cc}
\hline Number & Name \\
\hline 1 & Datong Township \\
2 & Nanao Township \\
3 & Suao Township \\
4 & Dongshan Township \\
5 & Sanxing Township \\
6 & Yuanshan Township \\
7 & Jiaoxi Township \\
8 & Yilan City \\
9 & Luodong Township \\
10 & Wujie Township \\
11 & Zhuangwei Township \\
12 & Toucheng Township \\
\hline
\end{tabular}

In addition, Yilan County has frequently had inundation problems in the last two decades. Grid data of inundation potential maps provided by Water Resources Agency (WRA), Taiwan's Ministry of Economic Affairs are used as the data of hazard in this study. The details of the inundation potential map as Table 2. Because this study aims at the qualification analysis for climate risk assessment, the climate risk template following the first to fourth steps of CCA6Steps is mainly operated to present the relationship between climate risk components. Therefore, the inundation potential maps with $350 \mathrm{~mm}$ and $600 \mathrm{~mm}$ of 24-h rainfall are regarded as current and future hazards to demonstrate 
spatial information of risk maps based on the investigation of climate adaptation strategies by the proposed algorithm.

Table 2. The details of the inundation potential map from the Water Resources Agency (WRA).

\begin{tabular}{lll}
\hline & Description \\
\hline 1. Historical Typhoon Event Data & & \\
& - Time period: $2008 \sim 2015$ \\
- & All typhoons and extreme rainfall events were included \\
- Some real-time data from inundation event for \\
\end{tabular}

2. Geographical Data

- $\quad$ Time period: 2011 2012

- Resolution: $1 \mathrm{~m} \times 1 \mathrm{~m}$

3. Drainage System

- $\quad$ County-level stream, drainage system, fish farm and irrigation channel (width above $5 \mathrm{~m}$ ) are included.

4. Hydraulic Infrastructure

- The infrastructure before 2015 were included.

\begin{tabular}{|c|c|}
\hline 5. Flood Model & - $\quad$ SOBEK model \\
\hline 6. Calibration and Verification & $\begin{array}{l}\text { - Typhoon and extreme rainfall events were included } \\
\text { - Checked the correlation, efficiency, accuracy and peak } \\
\text { deviation based on regulation guideline } \\
\text { - Stakeholder engaged as a kind of verification }\end{array}$ \\
\hline 7. Precipitation Data & $\begin{array}{l}\text { - Time period: 1985 2014 (continuous) } \\
\text { - } \quad \text { Horner design hyetograph }\end{array}$ \\
\hline 8. Scenarios & $\begin{array}{l}\text { - Precipitation duration: } 9 \text { different precipitation scenarios } \\
\text { for } 6 \mathrm{~h}, 12 \mathrm{~h} \text { and } 24 \mathrm{~h} \\
\text { - Inundation duration: } 6 \mathrm{~h} \text { and } 12 \mathrm{~h}\end{array}$ \\
\hline
\end{tabular}

As for the factors of vulnerability of the protected target for flood risk, reasonable causes in terms of selecting these vulnerability factors are as follows [26-30]: (1) Population for young children and older people: based on a human or economic perspective, the degree of hazards will be associated with the population of the affected area, especially for children and the elderly; (2) Poverty level: the percentage of people living below the lower poverty line in an area represents the poverty level (in general, a poor community is not only economically vulnerable but simultaneously have lack of social and political capacities to cope with disasters.); (3) Female to male ratio: number of women to number of men in an area due to the consideration of the possibility of pregnancy for females. Moreover, considering the unavailability of some data, the significant main factors such as population of young children, population of older people, poverty level, and female to male ratio are hence 
selected as the factors of vulnerability in this study. The numbers of people in administrative districts in Yilan County are regarded as the data of exposure. The data of exposure and vulnerability factors are totally collected from Department of Household Registration, Taiwan's Ministry of the Interior.

\section{Results}

To demonstrate the operation procedure of the proposed algorithm, CCA6Steps, the application of climate risk assessment for inundation disaster in Yilan County, was conducted. The result is focused on presenting how to apply the climate risk template based on the first to fourth steps of CCA6Steps. The first step, the identification of the key issue for inundation disaster, is discussed in Section 4.1. Section 4.2 is related to the second and third steps. Finally, the investigation of climate adaptation strategies for decreasing climate risk, representing the fourth step, is shown in Section 4.3. The study is expected that the proposed algorithm is able to assist users from different governance level to distinguish the relationship among risk components, which are hazard, exposure, and vulnerability.

\subsection{Identification of the Problems for Inundation Disaster}

In this study, the first step is to identify the problems for inundation disaster, as shown in Figure 6. The WRA was taken as the national governance level herein to implement the proposed algorithm. The stakeholders related to the government, key issue, and protected target with national, county, and community levels were respectively listed for the stakeholder engagement, for which the key issue was refined during the engagement process. Residents were selected as the protected target. According to the protected target, the exposure risk components were defined as the spatial distribution of residents. For example, based on the key issue and protected target, an identical flood would threat residents in a city area but do no harm in the original mountain region without people. Hence, there are no risks in those regions without the exposure of the protected target. In addition, the definition of hazard must contain two critical elements, hazard type and threshold. For instance, hazard is defined as levels of different inundation depths herein. Inundation depths represent the hazard type and level is regarded as the threshold. After these factors have been decided and filled in through the stakeholder engagement, the key issue is eventually determined as the effect of inundation on residents. However, the misunderstanding might impede the process of climate risk assessment. Therefore, the stakeholder engagement in the first step is aimed to aid consistency among government and other stakeholders, which would provide an explicit orientation for later analysis.

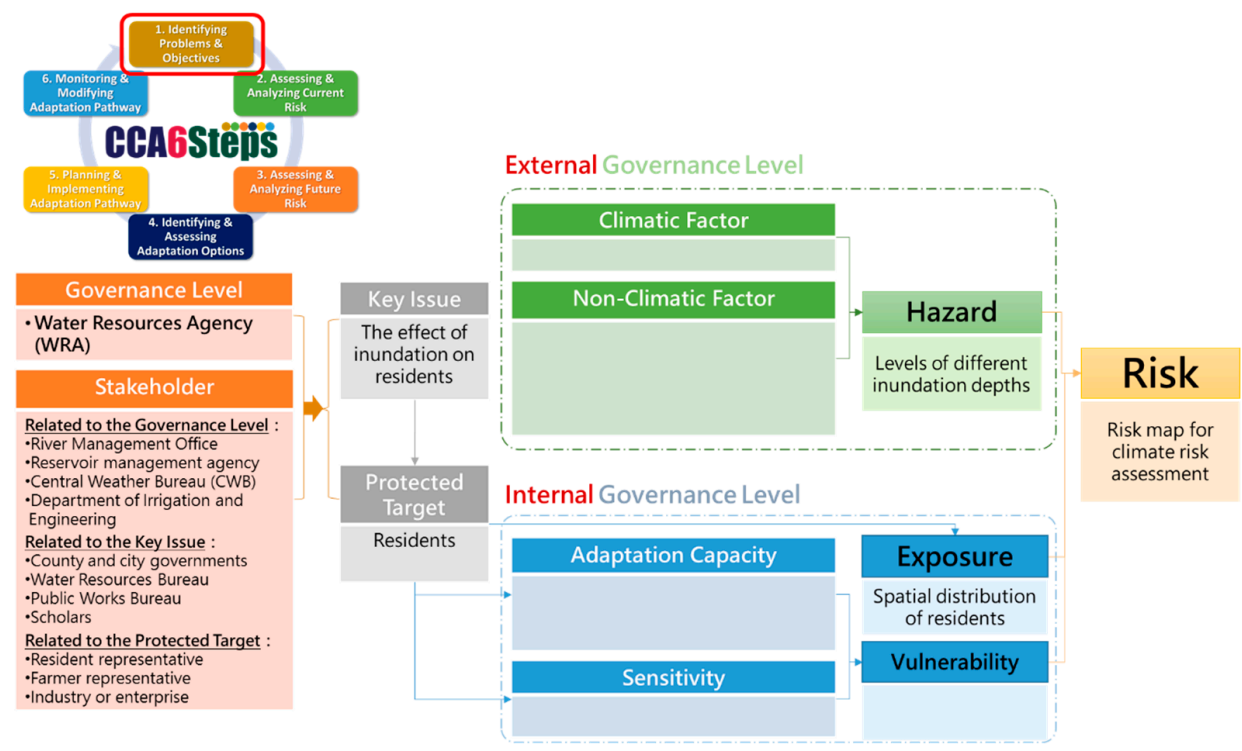

Figure 6. The proposed algorithm of climate risk assessment for investigating the relationship between factors based on Step 1 of CCA6Steps. 


\subsection{Current and Future Risk Analysis and the Demonstration of the Spatial Assessment of Climate Risk}

To conduct current and future risk analysis, the second and third steps of CCA6Steps, the risk is required to be fully factorized into the three risk components, which are hazard, exposure, and vulnerability. As shown in Figure 7, all factors were separated into external and internal governance levels, which consist of hazard and the other two risk components, respectively. In the external part, the climatic and non-climatic factors of the hazard (i.e., inundation depths) have been clearly investigated for assessing the current and the future risk. The climatic factor is extreme rainfall and non-climatic factors are river flow, water level, tidal level, elevation, slope, etc. The non-climatic factors might be caused by climatic factors such as river flow, water level, and tidal level, while those factors are not direct climate elements. Hence, as the definition of risk template, this study classified them as non-climatic factors. In the internal part, the exposure was defined in Section 4.1. Vulnerability is presented as indicators formed by adaptation capacity and sensitivity. At this stage the adaptation capacity only contained the adaptation capacity of residents, which are, for example, retaining plate and sandbags. On the other hand, sensitivity indicated the tolerance of the protected target itself toward the hazard. For the effect of inundation on residents, it might be the population of young children, population of older people, poverty level, and female to male ratio.

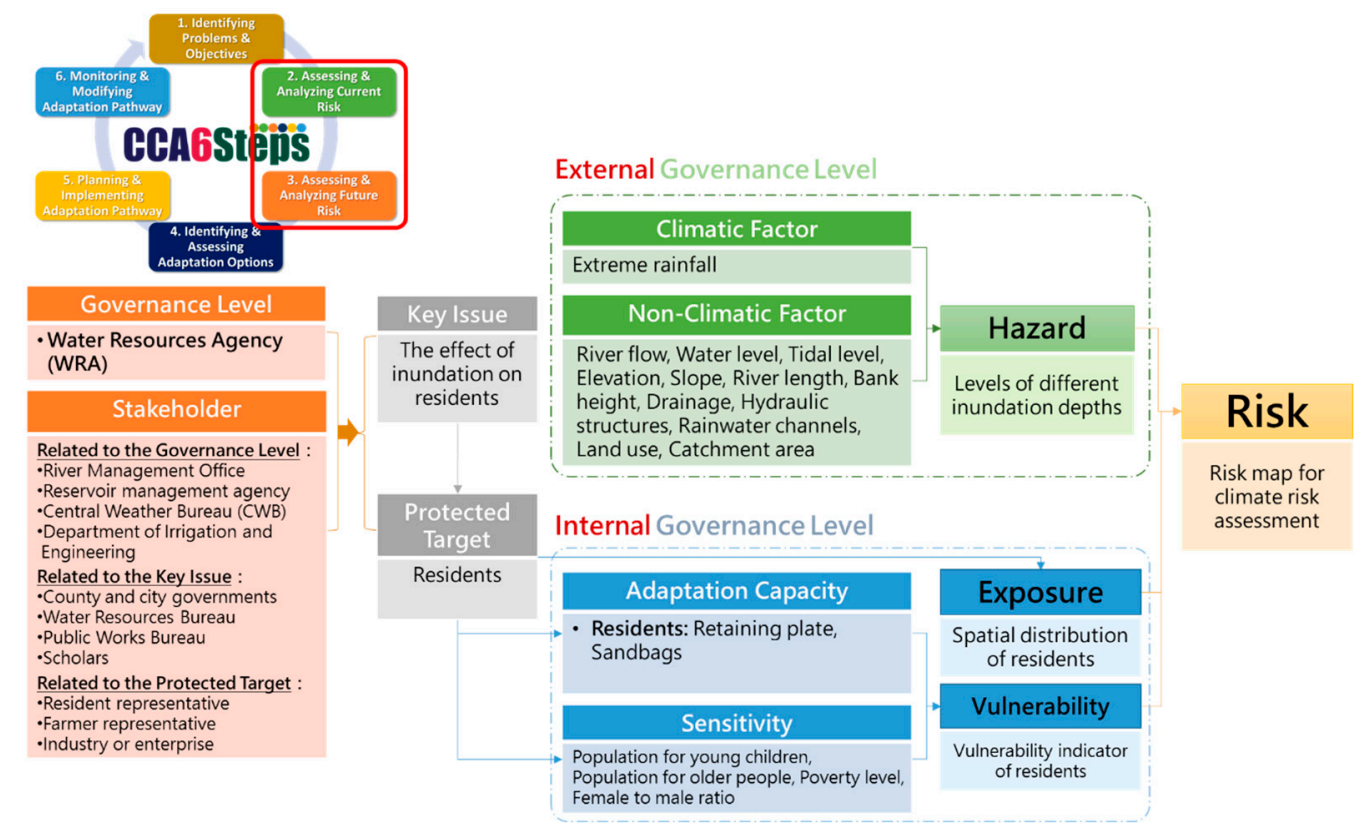

Figure 7. The proposed algorithm of climate risk assessment for investigating the relationship between factors based on Steps 2 and 3 of CCA6Steps.

According to the analyzed results of the proposed algorithm for investigating the relationship between factors on the basis of the second and third steps of CCA6Steps, the kind of tools presenting the hazard, exposure, and vulnerability should be carefully chosen and listed to help users understand, as shown in Figure 8. In the external governance level, the process models or meta models can be applied to describe the relationships among the climatic and non-climatic factors and generate the information for quantifying hazard component. For example, the SOBEK, a numerical flood simulation model, can be regarded as a tool to output inundation depths. The information of inundation depth could be further transformed into indicators and form the hazard map.

In the internal governance level, corresponding tools are provided and explained to support users implementing exposure and vulnerability components. As mentioned above, exposure represents the spatial allocation of the protected target, hence the GIS tool is commonly adopted to analyze and to display the spatial information. On the other hand, vulnerability is composed of adaptation capacity 
and sensitivity factors. The data source of each factor was listed in the metadata table, as shown in Table 3. According to the operational results of the proposed algorithm, the users are able to clearly analyze the current and the future risk with all provided information. In this case, the procedure of CCA6Steps with the climate risk template is able to provide a standard operating procedure and support risk communication among users.

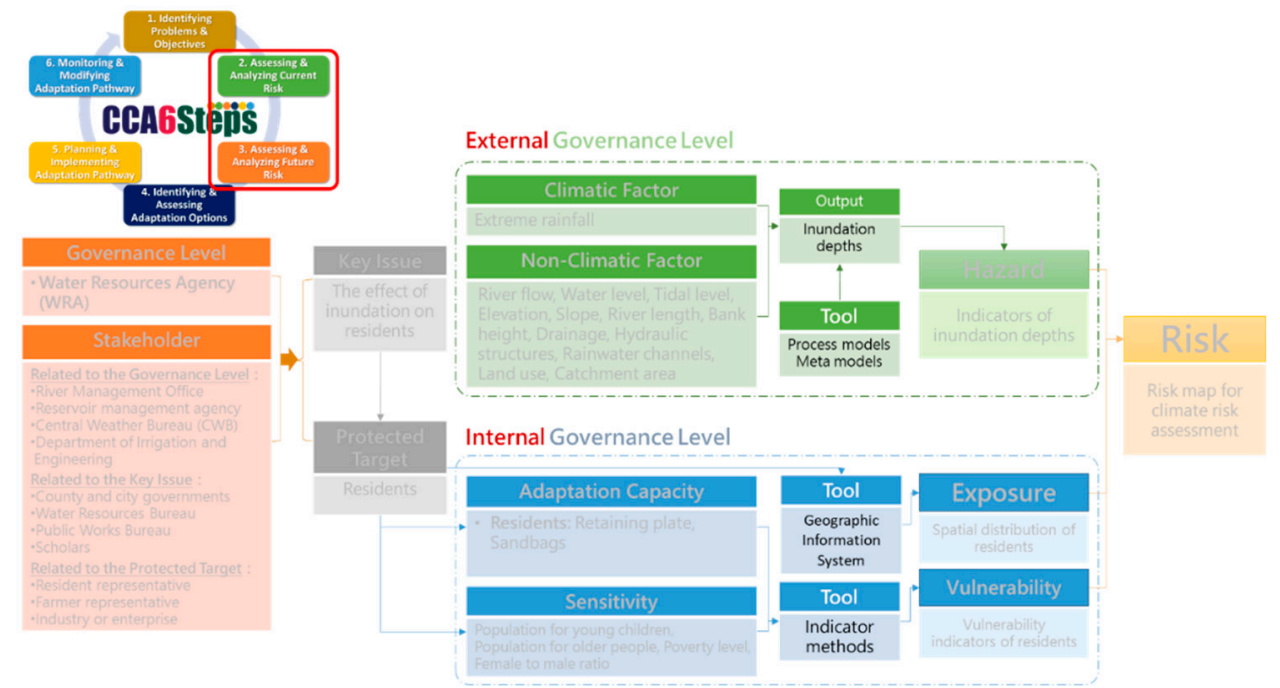

Figure 8. The proposed algorithm of climate risk assessment for presenting tools and indicators based on Steps 2 and 3 of CCA6Steps.

Table 3. The corresponding number for each administrative district of the study area.

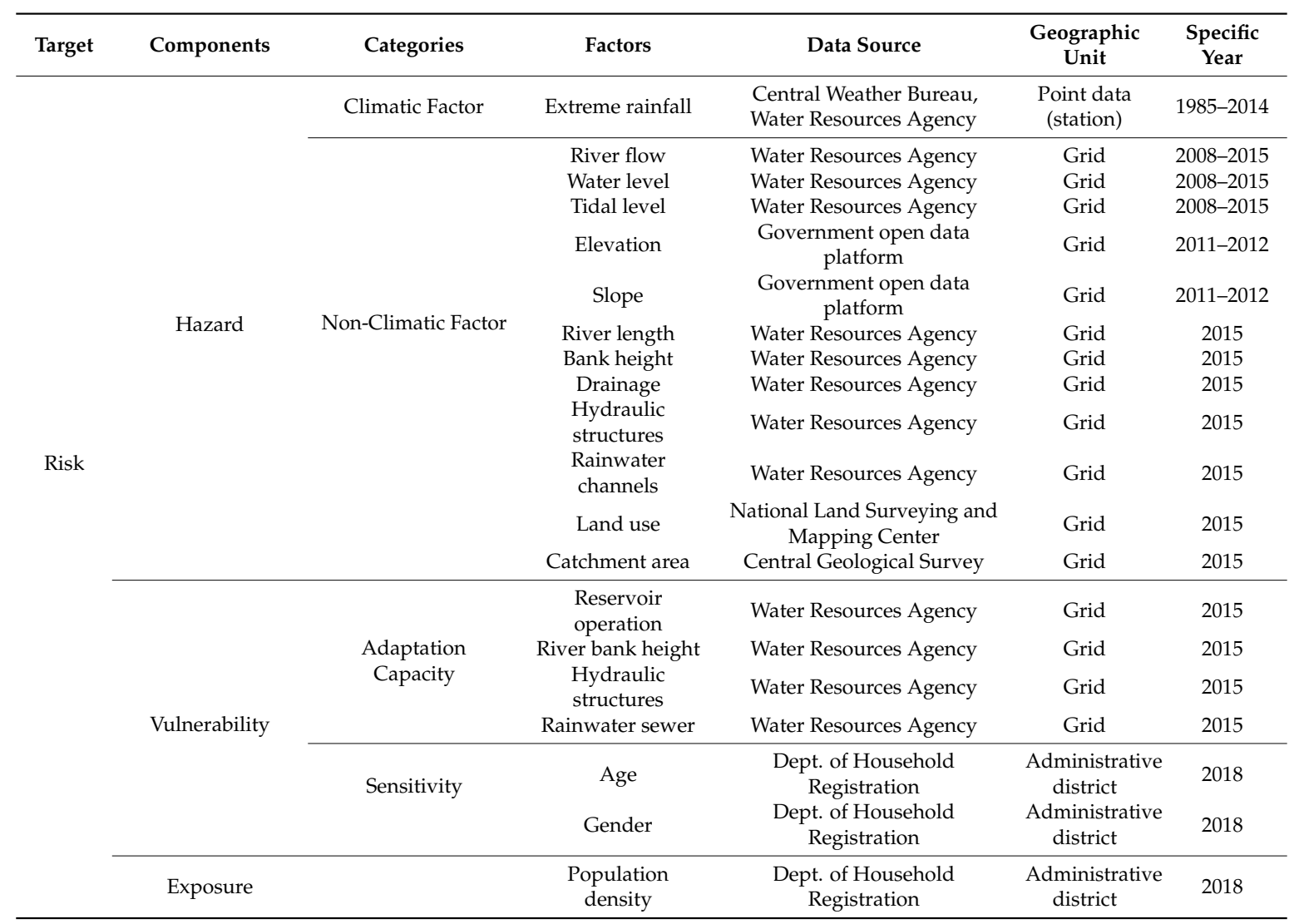


To demonstrate spatial information of risk maps based on the investigation of climate adaptation strategies by the proposed algorithm, the inundation potential maps with $350 \mathrm{~mm}$ and $600 \mathrm{~mm}$ of 24-h rainfall provided by the WRA are taken as current and future hazards to be an example, since this study aims at the qualification analysis for climate risk assessment. The assessment results in the form of risk maps with the resolution of administrative district are displayed, as shown in Figure 9. It was able to explicitly pinpoint districts that urgently need adaptation to alleviate future inundation risk. For example, the inundation risk increased one level in Sanxing township (Area 5), Jiaoxi township (Area 7), and Yilan city (Area 8) in the future scenario. What is more, in Figure 9b, Yilan city indicated the severest risk, which might be caused by its high population. Moreover, low elevation of districts closed to the bay-shape region results in a greater risk in both current and future scenarios.

(a)

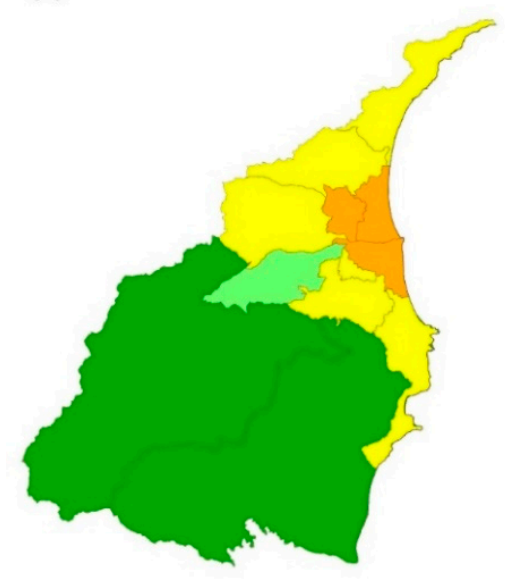

(b)

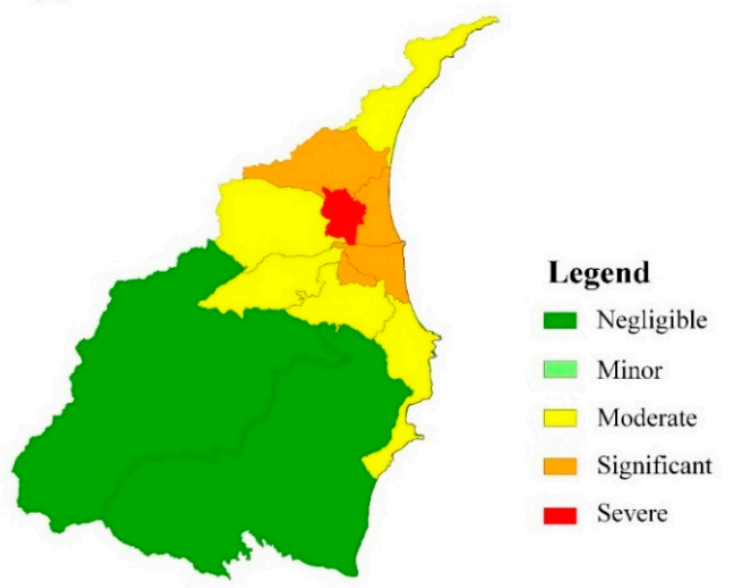

Figure 9. The risk assessment results for (a) the current and (b) the future scenarios by using the proposed algorithm of climate risk assessment based on Steps 2 and 3 of CCA6Steps.

\subsection{Investigation of Climate Adaptation Strategies for Decreasing Climate Risk}

According to the information provided through the first to third steps of CCA6Steps, the fourth step aims to investigate the climate adaptation strategies. Besides the residents' adaptation capacity, the adaptation capacity of the government should also be considered. As shown in Figure 10, the red dot arrow line is added to link the adaptation capacity of governance level to hazard since those adaptation strategies could fundamentally alter the constituents of hazard component and change the level of impact toward the protected target. In this study, the adaptation capacity of the government is referred to adaptation strategies from the WRA, such as reservoir operation, river bank height, hydraulic structures, and rainwater sewer. All of these strategies tend to strengthen non-climate factors in order to alleviate the hazard component, which results in ameliorating the inundation risk.

For example, improving reservoir operation, such as flood control operation releasing water before extreme rainfall events occur, creates a buffer capacity to reduce the water volume causing flood. Increasing river bank height and intensifying hydraulic structures could prevent the river overflow. In contrast to impeding overflows, the reinforcement of rainwater sewer accelerates the recession of a flood, which also benefits the reduction of hazard. Finally, through analyzing each proposed adaptation strategy, stakeholders are well-informed with the effectiveness of adaptation strategies and ready for further discussion. 


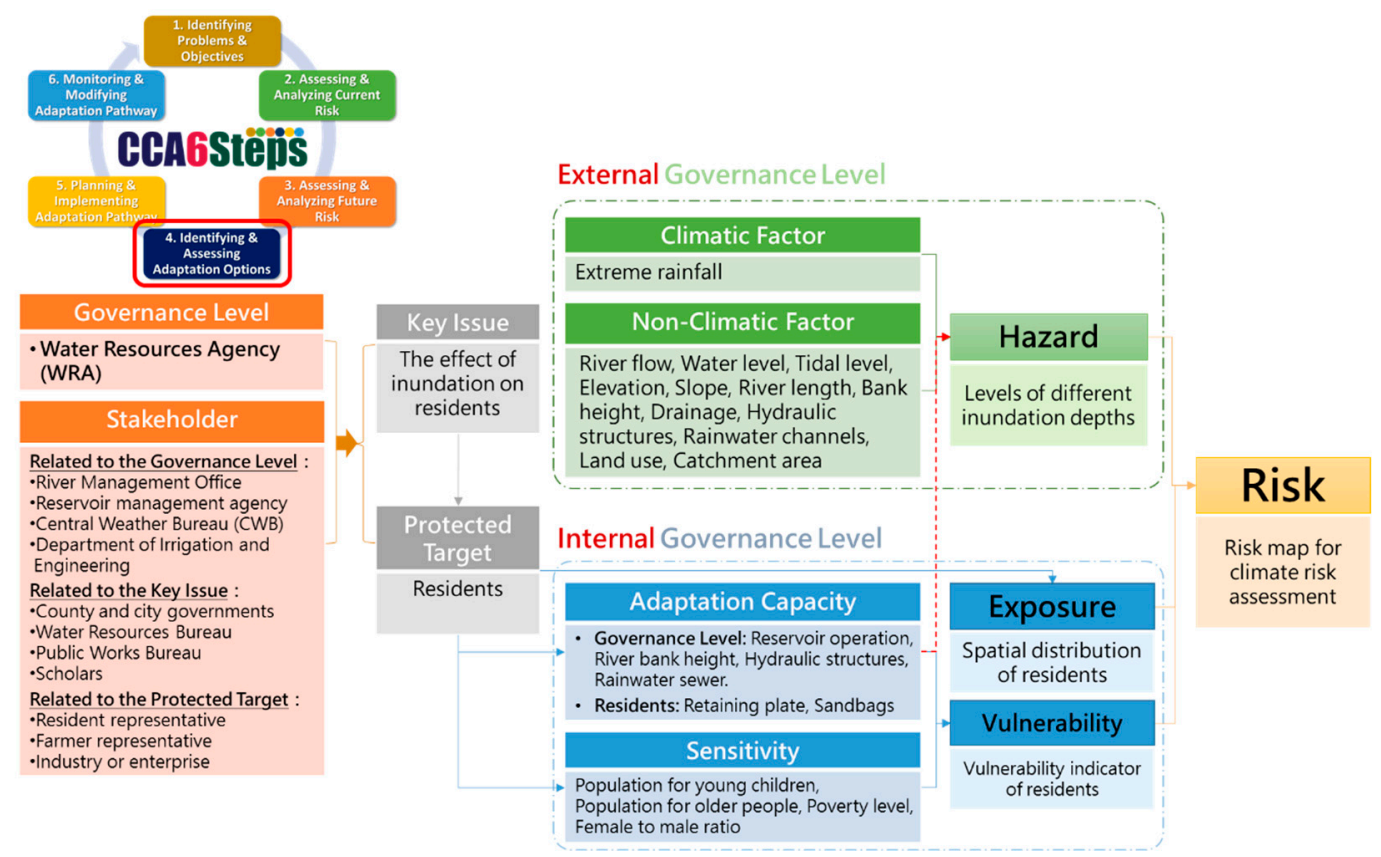

Figure 10. The proposed algorithm of climate risk assessment for investigating the relationship between factors based on Step 4 of CCA6Steps.

\section{Discussion}

According to the results of the case study, identification of the problems is a vital step during the whole assessment procedure. Inundation disasters resulting from excessive rainfall usually cause loss of human life and property. Climate extremes, especially for heavy precipitation, are the critical drivers of meteorological hazards, which might exacerbate the situation. The government is forced to face the problem and to be responsible to the protected target. Therefore, the assessment in the identification of the problems step is significant for concretizing and converging the key issue by the analysis of all possible factors and discussion with stakeholders. This step not only clarifies the protected target, the key issue, and structure of the risk, but also constructs a common picture among stakeholders. The results in the first step of CCA6Steps would provide an explicit orientation for later analysis.

During the second and third steps, three risk components were investigated and filled in the risk template. Hazard and exposure can be straightforwardly translated from the output of process models or meta models. However, vulnerability is difficult to calculate through those kinds of models. Therefore, an indicator method is recommended to quantify the vulnerability, for example, by weighting each factor of vulnerability component. Since the weighing process is highly user-oriented, the study result is only one possible outcome. Moreover, the results of current and future risk in Section 4.2 are sufficient to diagnose the trend of risk. However, it might not be enough for governance purpose, and might not be readable and understandable for every stakeholder. The spatial information and visualization, in this case, are necessary during the discussion process, especially for investigating climate adaptation strategies. Therefore, suitable visualization, such as the risk map, was shown in Figure 9.

With the risk map, the quality of communication between stakeholders could be enhanced. In order to explicitly describe the proposed climate algorithm, this case study only qualitatively demonstrates one application of the proposed algorithm. The quantitative example would further be valuable future work on topics of integrating the aspects of qualification and quantification. In addition, in Section 4.3, the case study result indicates the relationship between adaptation strategies and other factors, especially the link from adaptation toward hazard. The effects of each adaptation strategies were also explained. In the future, with decision rules and monitoring and modified method, the remaining fifth to sixth steps are able to be achieved and the full set of CCA6Steps can be completed. 


\section{Conclusions}

The purpose of this study is to inherently assess climate risk components. For this purpose, the climate adaptation algorithm, based on the procedure of Climate Change Adaptation Six Steps (CCA6Steps) integrated with the climate risk template, is proposed to identify the relationship between the climate risk components, including hazard, exposure, and vulnerability. This study also aims to provide an algorithmic process which distinguishes input data, parameter, tools, and result. Thus, different users will use the same protocol to announce risk map and adaption pathway. In this standardized way, the reliable data helps risk communication and cross-disciplinary research [31]. Yet, "algorithmization" brings innovation due to the wide suitability and reliability. An application is conducted to demonstrate the advantages of the proposed algorithm in this study. The results clearly show that the problems and objectives which concern the government and stakeholders can be clearly clarified in the first step of CCA6Steps. The current and future risks factorized into three risk components, which are hazard, exposure, and vulnerability, are also fundamentally analyzed by the second and third steps of CCA6Steps. Moreover, the climate adaptation strategies of the protected target and governance level are further investigated in the fourth step of CCA6Steps to alleviate the hazard component. In conclusion, the proposed climate adaptation algorithm is expected to provide a standard operating procedure and support risk communication among users for climate risk assessment.

Author Contributions: Conceptualization, C.-P.T., J.-H.T. and B.-C.J.; Methodology, C.-P.T., J.-H.T., Y.-C.T. and B.-C.J.; Software, C.-Y.L. and B.-C.J.; Data curation, J.-H.T., Y.-C.T., C.-Y.L. and B.-C.J.; Writing-Original Draft Preparation, Y.-C.T., C.-Y.L. and B.-C.J.; Writing-Review and Editing, J.-H.T., Y.-C.T., C.-Y.L. and B.-C.J.; Visualization, B.-C.J.; Supervision, C.-P.T. and B.-C.J.; Funding Acquisition, C.-P.T.

Funding: This research was funded by Ministry of Science and Technology (MOST) of Taiwan (Project Name: Study on E-Infrastructure of Climate-Smart Water Service, MOST 107-2621-M-002-002- ).

Acknowledgments: The authors would like to thank all colleagues and students from SDLAB who contributed to this study.

Conflicts of Interest: The authors declare no conflict of interest.

\section{References}

1. Croce, P.; Formichi, P.; Landi, F.; Castelluccio, R. Use of weather generators to assess impact of climate change: Thermal actions on structures. In Fifth International Conference Advances in Civil, Structural and Mechanical Engineering-CSM 2017; Institute of Research Engineers and Doctors: New York, NY, USA, 2017; pp. 32-36.

2. Araos, M.; Berrang-Ford, L.; Ford, J.D.; Austin, S.E.; Biesbroek, R.; Lesnikowski, A. Climate change adaptation planning in large cities: A systematic global assessment. Environ. Sci. Policy 2016, 66, 375-382. [CrossRef]

3. Ayeb-Karlsson, S.; van der Geest, K.; Ahmed, I.; Huq, S.; Warner, K. A people-centred perspective on climate change, environmental stress, and livelihood resilience in Bangladesh. Sustain. Sci. 2016, 11, 679-694. [CrossRef] [PubMed]

4. McIver, L.; Kim, R.; Woodward, A.; Hales, S.; Spickett, J.; Katscherian, D.; Hashizume, M.; Honda, Y.; Kim, H.; Iddings, S.; et al. Health impacts of climate change in Pacific island countries: A regional assessment of vulnerabilities and adaptation priorities. Environ. Health Perspect. 2015, 124, 1707-1714. [CrossRef] [PubMed]

5. Mann, M.E.; Rahmstorf, S.; Kornhuber, K.; Steinman, B.A.; Miller, S.K.; Coumou, D. Influence of anthropogenic climate change on planetary wave resonance and extreme weather events. Sci. Rep. 2017, 7, 45242. [CrossRef] [PubMed]

6. Sisco, M.R.; Bosetti, V.; Weber, E.U. When do extreme weather events generate attention to climate change? Clim. Chang. 2017, 143, 227-241. [CrossRef]

7. The Intergovernmental Panel on Climate Change (IPCC). Climate Change (IPCC). Climate change 2014: Impacts, adaptation, and vulnerability. Part A: Global and sectoral aspects. In Contribution of Working Group II to the Fifth Assessment Report of the Intergovernmental Panel on Climate Change; Cambridge University Press: Cambridge, UK; New York, NY, USA, 2014. 
8. African Development Bank; Asian Development Bank; Department for International Development, United Kingdom; Ministry of Foreign Affairs-Development Cooperation, The Netherlands; Directorate-General for Development, European Commission; Federal Ministry for Economic Cooperation and Development, Germany; Organization for Economic Cooperation and Development; United Nations Development Programme; United Nations Environment Programme; The World Bank. Poverty and Climate Change: Reducing the Vulnerability of the Poor through Adaptation; World Bank: Washington, DC, USA, 2003.

9. The Intergovernmental Panel on Climate Change (IPCC). Climate Change (IPCC). Climate Change 2001: Impacts, Adaptation, and Vulnerability. In Contribution of Working Group II to the Third Assessment Report of the Intergovernmental Panel on Climate Change; Cambridge University Press: Cambridge, UK; New York, NY, USA, 2001.

10. The Intergovernmental Panel on Climate Change (IPCC). Climate Change (IPCC). Climate Change 2007: Impacts, Adaptation, and Vulnerability. In Working Group II Contribution to the Intergovernmental Panel on Climate Change Fourth Assessment Report; Summary for Policy Makers; Cambridge University Press: New York, NY, USA, 2007.

11. The United Nations Framework Convention on Climate Change (UNFCCC). Application of methods and tools for assessing impacts and vulnerability, and developing adaptation responses. In Background Paper by the UNFCCC Secretariat; FCCC/SBSTA/2004/INF.13; UNFCCC: Rio de Janeiro, Brazil, 2004.

12. Hurlimann, A.; Barnett, J.; Fincher, R.; Osbaldiston, N.; Mortreux, C.; Graham, S. Urban planning and sustainable adaptation to sea-level rise. Landsc. Urban Plan. 2014, 126, 84-93. [CrossRef]

13. Willows, R.I.; Connell, R.K. Climate Adaptation: Risk, Uncertainty and Decision-Making. In UKCIP Technical Report; UKCIP: Oxford, UK, 2003.

14. Lim, B.; Spanger-Siegfried, E. Adaptation Policy Frameworks for Climate Change: Developing Strategies, Policies and Measures; United Nations Development Programme: New York, NY, USA, 2004.

15. Creighton, J. How to Conduct a Shared Vision Planning Process; IWR Report 10-R-6; U.S. Army Institute for Water Resources: Alexandria, VA, USA, 2010.

16. Palmer, R.N.; Cardwell, H.E.; Lorie, M.A.; Werick, W. Disciplined planning, structured participation, and collaborative modeling-Applying shared vision planning to water resources. J. Am. Water Resour. Assoc. 2013, 49, 614-628. [CrossRef]

17. Langsdale, S.; Beall, A.; Bourget, E.; Hagen, E.; Kudlas, S.; Palmer, R.; Tate, D.; Werick, W. Collaborative modeling for decision support in water resources: Principles and best practices. J. Am. Water Resour. Assoc. 2013, 49, 629-638. [CrossRef]

18. Richards, C.; Blackstock, K.L.; Carter, C.E. Practical Approaches to Participation SERG Policy Brief No. 1; Macauley Land Use Research Institute: Aberdeen, UK, 2004.

19. Reed, M.S.; Fraser, E.D.G.; Dougill, A.J. An adaptive learning process for developing and applying sustainability indicators with local communities. Ecol. Econ. 2006, 59, 406-418. [CrossRef]

20. Broad, K.; Pfaff, A.; Taddei, R.; Sankarasubramanian, A.; Lall, U.; de Assis de Souza Filho, F. Climate, stream flow prediction and water management in northeast Brazil: Societal trends and forecast value. Clim. Chang. 2007, 84, 217-239. [CrossRef]

21. Haasnoot, M.; van't Klooster, S.; van Alphen, J. Designing a monitoring system to detect signals to adapt to uncertain climate change. Glob. Environ. Chang. Hum. Policy Dimens. 2018, 52, 273-285. [CrossRef]

22. Petley, D. Global patterns of loss of life from landslides. Geology 2012, 40, 927-930. [CrossRef]

23. Sun, D.Y.; Zhang, D.W.; Cheng, X.T. Framework of National Non-Structural Measures for Flash Flood Disaster Prevention in China. Water 2012, 4, 272-282. [CrossRef]

24. Datta, S.; Mukherjee, S.K. Developing a risk management matrix for effective project planning-an empirical study. Proj. Manag. J. 2001, 32, 45-57. [CrossRef]

25. Pan, T.Y.; Chang, L.Y.; Lai, J.S.; Chang, H.K.; Lee, C.S.; Tan, Y.C. Coupling typhoon rainfall forecasting with overlandflow modeling for early warning of inundation. Nat. Hazards 2014, 70, 1763-1793. [CrossRef]

26. Ballesteros, C.; Jiménez, J.A.; Viavattene, C. A multi-component flood risk assessment in the Maresme coast (NW Mediterranean). Nat. Hazards 2018, 90, 265-292. [CrossRef]

27. Shahid, S.; Behrawan, H. Drought risk assessment in the western part of Bangladesh. Nat. Hazards 2008, 46, 391-413. [CrossRef]

28. Ruiter, M.C.D.; Ward, P.J.; Daniell, J.E.; Aerts, J.C. A comparison of flood and earthquake vulnerability assessment indicators. Nat. Hazards Earth Syst. Sci. 2017, 17, 1231-1251. [CrossRef] 
29. Sayers, P.; Penning-Rowsell, E.C.; Horritt, M. Flood vulnerability, risk, and social disadvantage: Current and future patterns in the UK. Reg. Environ. Chang. 2018, 18, 339-352. [CrossRef]

30. Wang, Y.; Li, Z.; Tang, Z.; Zeng, G. A GIS-based spatial multi-criteria approach for flood risk assessment in the Dongting Lake Region, Hunan, Central China. Water Resour. Manag. 2011, 25, 3465-3484. [CrossRef]

31. Gordon, D.J.; Johnson, C.A. The orchestration of global urban climate governance: Conducting power in the post-Paris climate regime. Environ. Politics 2017, 26, 694-714. [CrossRef] 